\title{
Primary Gallbladder Cancer Discovered Postoperatively after Elective and Emergency Cholecystectomy
}

\author{
Primární rakovina žlučníku diagnoastikovaná pooperačně \\ po elektivní a hospitalizační cholecystektomii
}

loannidis O. ${ }^{1}$, Paraskevas G. ${ }^{2}$, Varnalidis I. ${ }^{3}$, Ntoumpara M. ${ }^{1}$, Tsigkriki L. ${ }^{1}$, Gatzos S. ${ }^{1}$, Malakozis S. G. ${ }^{1}$ Papapostolou D. ', Papadopoulou A. ${ }^{1}$, Makrantonakis A. ${ }^{1}$, Makrantonakis N. ${ }^{1}$

'First Surgical Department, General Regional Hospital 'George Papanikolaou', Thessaloniki, Greece 2Department of Anatomy, Medical School, Aristotle University of Thessaloniki, Thessaloniki, Greece ${ }^{3}$ Plastic Surgery Department, General Regional Hospital 'George Papanikolaou', Thessaloniki, Greece
The authors declare they have no potential conflicts of interest concerning drugs, products, or services used in the study.

Autoři deklarují, že $v$ souvislosti s předmětem studie nemají žádné komerční zájmy.

The Editorial Board declares that the manuscript met the ICMJE "uniform requirements" for biomedical papers.

Redakční rada potvrzuje, že rukopis práce splnil ICMJE kritéria pro publikace zasílané do biomedicínských časopisů.

Orestis loannidis, MD

Alexandrou Mihailidi 13

54640 Thessaloniki

Greece

e-mail: telonakos@hotmail.com

Submitted/Obdrženo: 13. 11. 2012 Accepted/Přijato: 26. 11. 2012 


\section{Introduction}

Gallbladder cancer (GC), first described in 1777 by Stroll [1-5], is a relatively rare neoplasm; it is the fifth most common malignancy of the gastrointestinal tract and has been considered to be a highly lethal disease [2-4,6-9]. It is most common among the elderly, especially in the $7^{\text {th }}$ and $8^{\text {th }}$ decade of life [7]. Frequency of $\mathrm{GC}$ at cholecystectomy increases along with age. Below the age of 50, the frequency of GC is about $0.25 \%$, between ages $50-64$ it is about $3.1 \%$, increasing to $9.1 \%$ at ages $65-74$ and to $11.9 \%$ over age 75 [10]. The ratio of men to women is $1 / 3$ or $1 / 4$ [1-9,11]. GC presents a variable geographic distribution and both genetic and environmental risk factors seem to contribute in the development of GC [1-9].

\section{Purpose}

The purpose of this study is to present our experience in postoperatively discovered incidental gallbladder cancer in the period of 1992-2001.

\section{Methods and Material}

For the present retrospective study, the hospitalization, surgical and histopathological records of our department were examined from January 1992 to December 2001, searching for patients who had undergone cholecystectomy. Furthermore, the histopathological diagnoses of the same period were studied searching for patients with gallbladder cancer.

\section{Results}

During this 10 -year period a total of 1,536 cholecystectomies took place. Fourteen cases of primary gallbladder cancer were found postoperatively. The ratio of women to men was $11 / 3$ and the ages ranged from 59 to 87 years with a mean age of 69.4 years.

The clinical signs were: acute cholecystitis $(5 / 14,35.7 \%)$, right upper quadrant pain $(6 / 14,42.86 \%)$, obstructive jaundice $(1 / 14,7.14 \%)$, a combination of right upper quadrant pain and jaundice $(7.14 \%)$ and one patient was asymptomatic (7.14\%). One case (7.14\%) of porcelain gallbladder was found preoperatively.
The treatment included open cholecystectomy $(11 / 14,78.6 \%)$ and laparoscopic cholecystectomy $(3 / 14,21.4 \%)$. Also, a Kehr tube was inserted into two patients. In all but two cases, gallstones (85.7\%) were present and in $4 / 14 \mathrm{pa}-$ tients $(28.57 \%)$ gallbladder empyema was found intraoperatively.

The diagnosis was accomplished postoperatively by histopathological examination. All cases of GCs were adenocarcinomas. The staging of the patients is presented in Tab. 1.

Patients of $\mathrm{T} 2$ stage and $\mathrm{T} 3$ stage were referred to a hepatobiliary surgery department for further treatment and all patients were further referred to the oncological department after the surgical intervention (data not included) but with poor results. The mortality rate was $57 \%$ (8/14 patients).

\section{Discussion}

There are many risk factors including genetic and environmental that are related to gallbladder carcinogenesis [12-15]. Females are affected by GC more commonly than males and the majority of patients are over 40 years old $[14,16]$. A correlation between GC and multiple familial polyposis/Gardner syndrome, Peutz-Jeghers syndrome, porcelain gallbladder and anomalous pancreato-biliary ductal union has also been reported. A progression from adenoma to carcinoma has been demonstrated within adenomatous polyps of the gallbladder [17]. However, the majority of gallbladder polyps are benign cholesterol polyps [16]. Chronic infection by Salmonella may also be an important causative factor in the pathogenesis of gallbladder cancer $[14,16]$. The prevalence of GC is increased among workers in the oil, paper, chemical, shoe, textile, and cellulose acetate fibre manufacturing industries suggesting occupational exposure to carcinogens [14]. All the above factors are debatable and do not explain the full picture. The correlation of GC with cholelithiasis is well established [18]. Geographical variability of gallbladder cancer incidence correlated with the prevalence of gallstones is reported [14]. High incidence rate is found among Chileans, Bolivians,
North American Indians, Mexican-Americans and Central Europeans [14] all of whom also have high prevalence of cholelithiasis. On the other hand, African Americans present the lowest incidence rate. The estimated incidence in the United States is $1: 100,000$ for men and $2: 100,000$ for women, corresponding to 5,000 new cases each year [13]. Gallstones are present in $74-92 \%$ of patients with gallbladder cancer. In a cohort study conducted in the United States, the relative risk of developing gallbladder cancer in patients with gallstone disease was 8.3 compared to the general population [19]. Relative risk ranges widely from 2.3 to 34.4 between different studies [20]. However, the minority of patients (less than one percent) with cholelithiasis develops gallbladder cancer and approximately $20 \%$ of gallbladder cancer patients show no evidence of previous cholelithiasis [14]. The coexistence of gallstones in GC indicates at least a role of a co-factor but the existence of multiple factors that lead to $\mathrm{GC}$ is more possible. There are plentiful studies about the correlation between gallstones and gallbladder cancer $[6,15,21,22]$. Long duration of gallstones, more stones, larger and heavier, infection, and type of stone is believed to lead to dysplastic and eventually malignant changes in the gallbladder mucosa.

GC is usually found incidentally and approximately $1 \%$ of patients who undergo cholecystectomy for cholecystitis have an unsuspected gallbladder cancer [10]. Premalignant changes, including epithelial hyperplasia, dysplasia and carcinoma, have been identified in 13.5, 8.3 and $3.5 \%$, respectively, of patients undergoing cholecystectomy for cholelithiasis or cholecystitis [23]. More than $90 \%$ of GC is well, to moderately differentiated adenocarcinomas. In our study all the cases were adenocarcinomas. Less common types include papillary, muqinous, squamous and adenosquamous [16]. Malignancy is usually diagnosed on pathological examination after simple cholecystectomy [6,14]. More GC arises in the fundus of the gallbladder (60\%), but GC may also occur in the body (30\%) and in the neck $(10 \%)[4,24]$. 
GC can be diagnosed: 1) preoperatively when malignancy is suspected, 2) at the time of cholecystectomy for presumed benign disease, or 3 ) incidentally on pathological examination after simple cholecystectomy. The last scenario is more common as the diagnosis is rarely accomplished preoperatively because of indolent progression of this type of tumor [2,4-7,12,14,25-28]. Patients with early stage gallbladder cancer are often asymptomatic and GC is diagnosed during routine cholecystectomy. The symptoms - nonspecific for gallbladder cancer - include pain in the right upper abdomen (73\%), nausea and vomiting (43\%), jaundice (37\%), weight loss and anorexia (35\%), flatulence, prickliness, hematemesis and melaena $[4,10]$. Patients with early stage gallbladder cancer are often asymptomatic. Jaundice is a bad prognostic sign pointing to cancer and is present in $45 \%$ of patients, one in five shows ascites and one in ten an obstruction of the duodenum on clinical presentation [29,30]. Increased levels of liver enzymes are also common. Seventy-five percent of patients are diagnosed when the disease is at advanced stages, beyond the limits of resection. It would be helpful to inspect the gallbladder mucosa after simple cholecystectomy. When malignancy is suspected lesions should be sent for frozen section histology.

It is certain that advances in preoperative imaging have occurred in the last years. Ultrasonography is usually the initial examination required, often when benign gallbladder disease is suspected. Gallbladder cancer may be presented as 1) a mass replacing the gallbladder or invading the gallbladder bed, 2) an intraluminal gallbladder growth or polyp, or 3) asymmetric gallbladder wall thickening. In cases of locally advanced disease, ultrasound has a sensitivity of $85 \%$ and an overall accuracy of $80 \%$ in diagnosing gallbladder cancer [30]. However, in an earlier stage disease, especially when the tumor or cancerous polyp is flat or sessile and is associated with cholelithiasis, ultrasonography may fail to detect the lesion [31]. Ultrasonographic examination is also helpful in staging the disease by showing the involvement of the biliary tract and the hepatic arterial or portal venous invasion. CT or MRI is also useful in staging the disease. It has been demonstrated that conventional MRI with associated MRA and MRCP can detect the presence of vascular invasion, biliary tract involvement, liver invasion and lymph node involvement [16]. 18F-fluorodeoxyglucose (FDG) positron emission tomography (PET) may also be useful in the preoperative evaluation of gallbladder cancer [32]. In one study, it has been reported that FDG-PET changed the management of nearly $25 \%$ of patients [33]. A sensitivity of $78 \%$ and a specificity of $80 \%$ for FDG-PET detecting residual primary disease and a sensitivity of $50 \%$ in detecting distant metastases or carcinomatosis have also been reported [16]. There is a relatively high risk of metastatic disease; two-thirds of patients with T3 lesions and over $80 \%$ of patients with $\mathrm{T} 4$ lesions have peritoneal spread $[9,17]$. The detection of peritoneal and small liver metastases is still difficult with standard imaging techniques. Staging laparoscopy was reported to be useful in detecting peritoneal and/or hepatic metastatic disease not identified on preoperative imaging [34].

The majority of the patients with GC are diagnosed at advanced stages and the prognosis is generally extremely poor [8]. The median survival for incidental carcinomas is 26.5 months and for suspected carcinomas is 9.2 months $[2,7,26]$. Important for the prognosis is the clinical or pathologic stage. The most commonly used is the TNM staging system $[14,16,35]$. In patients with GC stage III and IV, the 5-year survival rate was $52 \%$ after curative resection compared with the $5 \%$ 5-year survival rate after a non-curative resection [35]. The peritoneum and the liver are most commonly the sites of distant metastasis. The prognosis is better when the tumors are well-differentiated [10]. As determined by different studies, if negative margins were seen, patients achieved a 5-year survival rate as follows: stage I (90-60\%), stage II (56-80\%), stage III (15-40\%) and stage IV (5-10\%) [7,36,37].

GC is a significant challenge for laparoscopic surgery $[2,38]$. Survival is associated with the ability to achieve a com-
Tab. 1. T stage of the gallbladder cancer.

\begin{tabular}{lcc}
\hline Number & $\begin{array}{c}\text { Percentage } \\
\text { of patients }\end{array}$ & \\
T1 & 5 & $35.7 \%$ \\
T2 & 6 & $42.86 \%$ \\
T3 & 3 & $21.43 \%$ \\
T4 & 0 & $0 \%$ \\
TOTAL & 14 & $100 \%$ \\
\hline
\end{tabular}

plete tumor extirpation with negative histologic margins, a curative R0 resection $[9,10,16,22,39,40]$. Treatment is usually adjusted according to the staging: - Tis and T1a GC disease requires simple cholecystectomy (the reported 5-year survival rate is $85 \%$ ) $[16,22]$. For -T1b GC that invades the muscular layer of the gallbladder, controversial suggestions support either the simple cholecystectomy or radical resection [41-43]. T1b tumors may also require a lymphadenectomy or liver resection $[16,22,40]$. - T2 disease, which presents an incidence rate of lymph node metastasis that reaches $46 \%$, with most of the patients developing residual peritoneal seedings or disease in the lymph nodes after simple cholecystectomy, requires radical resection, as well, including en bloc resection of the adjacent liver and regional lymphadenectomy. Similarly, resection and reconstruction of the bile duct may be necessary. In T3 disease, which invades adjacent organs, such as extrahepatic bile ducts, liver, duodenum, pancreas, colon and stomach, it is suggested that simple cholecystectomy is inadequate and residual disease could lead to recurrence or death within 3 years [44]. T3 tumors require liver resection, regional lymphadenectomy, bile duct resection, en bloc resection of adherent tissues and adjacent organs. In T4 disease, which includes invasion of the main portal vein or hepatic artery or invasion of at least two extrahepatic organs or structures, complete surgical resection of bulky local disease is reported to increase the 5-year survival rate, while simple cholecystectomy for T3 and T4 disease showed absence of possibilities for 5 -year survival $[2,8,9,42,45,46]$. In advan- 
ced stages, in which survival is ascertained to be associated with the extent of resection, palliative treatment is proposed to relieve the pain, jaundice, cholangitis, bowel and gastric outlet obstruction for improvement of the quality of life [2]. T4 tumors are most of the times unresectable. In these cases palliative therapies may be helpful. It is reported that there is no consensus among surgeons as to justify whether reoperation or radical resection should be preferred at any case. Aggressive resection is reasonable, except for those patients with lymph node involvement outside the hepatoduodenal ligament and metastases. However, curative resection continues to be the only hope for survival in patients suffering from this lethal disease.

The role of chemotherapy in the treatment of GC must be further examined. For patients who present with unresectable tumors or recurrence after resection survival rates range between 2 and 4 months and palliation may be helpful to relieve symptoms [16]. Surgical bypass or endoscopically or radiologically placed drainage tubes might be necessary to relieve symptoms related to biliary obstruction [47]. Intestinal bypass should be performed if there is a small bowel obstruction. However, it should be considered that morbidity from surgical bypass is high. Adjuvant chemotherapy with 5-FU and mitomycin to resected gallbladder patients might have promising results [16]. Current studies in gallbladder and biliary tract cancers are focusing on gemcitabine-based chemotherapy or chemoradiotherapy. However, in general, palliative chemotherapy has yielded poor results as far as the treatment of unresectable gallbladder cancer is concerned. Several studies suggested a small improvement with radiation therapy either alone or in combination with systemic chemotherapy. Todoroki et al [48] reported an overall 5 -year survival rate of $9.1 \%$ following aggressive resection surgery for stage IV gallbladder carcinoma and adjuvant radiotherapy.

As far as prevention is concerned, primary prevention of gallbladder cancer is rather unlikely in the near future. Se- condary prevention is directed to the treatment of symptomatic gallstones, especially in endemic areas where cholelithiasis is highly prevalent [14]. Prophylactic laparoscopic cholecystectomy might be cost effective and its role should be further examined [15].

\section{References}

1. Goetze T, Paolucci V. Does laparoscopy worsen the prognosis for incidental gallbladder cancer? Surg Endosc 2006; 20(2): 286-293.

2. Gourgiotis S, Kocher HM, Solaini L et al. Gallbladder cancer. Am J Surg 2008: 196(2): 252-264.

3. Pandey M. Risk factors for gallbladder cancer: a reapp raisal. Eur J Cancer Prev 2003; 12(1): 15-24.

4. Reid KM, Ramos-De la Medina A, Donohue JH. Diagnosis and surgical management of gallbladder cancer: a re view. J Gastrointest Surg 2007; 11(5): 671-681.

5. Sheth S, Bedford A, Chopra S. Primary gallbladder cancer: recognition of risk factors and the role of prophylactic cholecystectomy. Am J Gastroenterol 2000; 95(6): 1402-1410. 6. Albores-Saavedra J, Alcantra-Vazquez A, Cruz-Ortiz H et al. The precursor lesions of invasive gallbladder carcinoma. Hyperplasia, atypical hyperplasia and carcinoma in situ. Cancer 1980; 45(5): 919-927.

7. Butte JM, Matsuo K, Gonen M et al. Gallbladder cance differences in presentation, surgical treatment, and survival in patients treated at centers in three countries. J Am Coll Surg 2011:212(1): 50-61.

8. Furlan A, Ferris JV, Hosseinzadeh K et al. Gallbladder carcinoma update: multimodality imaging evaluation, staging, and treatment options. AJR Am J Roentgenol 2008; 191(5): 1440-1447.

9. Mekeel $\mathrm{KL}$, Hemming AW. Surgical management of gallbladder carcinoma: a review. J Gastrointest Surg 2007; 11(9): 1188-1193.

10. Orth K, Beger HG. Gallbladder carcinoma and surgica treatment. Langenbecks Arch Surg 2000; 385(8): 501-508. 11. Sarli L, Contini S, Sansebastiano G et al. Does laparoscopic cholecystectomy worsen the prognosis of unsuspected gallbladder cancer? Arch Surg 2000; 135(11): 1340-1344.

12. Donohue JH. Present status of the diagnosis and treatment of gallbladder carcinoma. J Hepatobiliary Pancrea Surg 2001; 8(6): 530-534.

13. Donohue JH, Stewart AK, Menck HR. The Nationa Cancer Data Base report on carcinoma of the gallbladder 1989-1995. Cancer 1998; 83(12): 2618-2628.

14. Lazcano-Ponce EC, Miquel JF, Munoz N et al. Epidemiology and molecular pathology of gallbladder cancer. CA Cancer J Clin 2001; 51(6): 349-364.

15. Shrikhande SV, Barreto SG, Singh S et al. Cholelithiasis in gallbladder cancer: coincidence, cofactor, or cause! Eur J Surg Oncol 2010; 36(6): 514-519.

16. Miller G, Jarnagin WR. Gallbladder carcinoma. Eu J Surg Oncol 2008; 34(3): 306-312.

17. Fong Y, Malhotra S. Gallbladder cancer: recent advances and current guidelines for surgical therapy. Adv Surg 2001; 35: 1-20

18. Perpetuo MD, Valdivieso M, Heilbrun LK et al. Natura history study of gallbladder cancer: a review of 36 years experience at M. D. Anderson Hospital and Tumor Institute Cancer 1978:42(1):330-335.

19. Maringhini A, Moreau JA, Melton LJ 3rd et al. Gallstones, gallbladder cancer, and other gastrointestinal malignancies. An epidemiologic study in Rochester, Minnesota. Ann Intern Med 1987: 107(1):30-35.

20. Randi G, Franceschi S, La Vecchia C. Gallbladder cance worldwide: geographical distribution and risk factors. Int Cancer 2006: 118(7): 1591-1602.

21. Roa I, Araya JC, Villaseca M et al. Preneoplastic le sions and gallbladder cancer: an estimate of the period required for progression. Gastroenterology 1996; 111(1): 232-236.
22. Shrikhande SV, Barreto SG. Surgery for gallbladder cancer: The need to generate greater evidence. World J Gastrointest Surg 2009: 1(1): 26-29.

23. Levin B. Gallbladder carcinoma. Ann Oncol 1999; 10 (Suppl 4): 129-130.

24. Ransohoff DF, Gracie WA. Treatment of gallstones. Ann Intern Med 1993; 119 (7 Pt 1): 606-619.

25. Steinert R, Nestler G, Sagynaliev E et al. Laparoscopic cholecystectomy and gallbladder cancer. J Surg Oncol 2006: 93(8): 682-689.

26. Wullstein C, Woeste G, Barkhausen S et al. Do complications related to laparoscopic cholecystectomy influence the prognosis of gallbladder cancer? Surg Endosc 2002; 16(5): 828-832.

27. Isambert M, Leux C, Metairie S et al. Incidentally-discovered gallbladder cancer: When, why and which reoperation? J Visc Surg 2011; 148(2): e77-84.

28. de Aretxabala X, Roa I, Burgos L et al. Gallbladder cancer: an analysis of a series of 139 patients with invasion restricted to the subserosal layer. J Gastrointest Surg 2006; 10(2): 186-192.

29. Dawes LG. Gallbladder cancer. Cancer Treat Res 2001; 109: 145-155

30. Hawkins WG, DeMatteo RP, Jarnagin WR et al. Jaundice predicts advanced disease and early mortality in patients with gallbladder cancer. Ann Surg Oncol 2004; 11(3): 310-315

31. Onoyama H, Yamamoto M, Takada M et al. Diagnostic imaging of early gallbladder cancer: retrospective study of 53 cases. World J Surg 1999; 23(7): 708-712.

32. Hueman MT, Vollmer CM Jr. PawlikTM. Evolving treatment strategies for gallbladder cancer. Ann Surg Oncol 2009; 16(8): 2101-2115.

33. Corvera CU, Blumgart LH, Akhurst T et al. 18F-fluorodeoxyglucose positron emission tomography influences management decisions in patients with biliary cancer. J Am Coll Surg 2008; 206(1): 57-65.

34. Weber SM, DeMatteo RP, Fong Y et al. Staging laparoscopy in patients with extrahepatic biliary carcinoma. Analysis of 100 patients. Ann Surg 2002; 235(3): 392-399. 35. Tsukada K, Hatakeyama K, Kurosaki I et al. Outcome of radical surgery for carcinoma of the gallbladder according to the TNM stage. Surgery 1996; 120(5): 816-821. 36. Pearlstone DB, Curley SA, Feig BW. The management of gallbladder cancer: before, during, and after laparoscopic cholecystectomy. Semin Laparosc Surg 1998: 5(2): 121-128. 37. Suzuki K, Kimura T, Ogawa H. Is laparoscopic cholecystectomy hazardous for gallbladder cancer? Surgery 1998; 123(3): 311-314

38. Shih SP, Schulick RD, Cameron JL et al. Gallbladder cancer: the role of laparoscopy and radical resection. Ann Surg 2007; 245(6): 893-901.

39. Darabos N, Stare R. Gallbladder cancer: laparoscopic and classic cholecystectomy. Surg Endosc 2004; 18(1): 144-147. 40. Pilgrim C, UsatoffV, Evans PM. A review of the surgical strategies for the management of gallbladder carcinoma based on T stage and growth type of the tumour. Eur J Surg Oncol 2009; 35(9): 903-907.

41. Jayaraman S, Jarnagin WR. Management of gallbladder cancer Gastroenterol Clin North Am 2010: 39(2): 331-342.

42. Misra S, Chaturvedi A, Misra NC et al. Carcinoma of the gallbladder. Lancet Oncol 2003; 4(3): 167-176.

43. Zhu AX, Hong TS, Hezel AF et al. Current management of gallbladder carcinoma. Oncologist 2010; 15(2): 168-181. 44. Yamaguchi K, Tsuneyoshi M. Subclinical gallbladder carcinoma. Am J Surg 1992; 163(4): 382-386.

45. Bartlett DL, Fong Y, Fortner JG et al. Long-term results after resection for gallbladder cancer. Implications for staging and management. Ann Surg 1996; 224(5): 639-646. 46. Shirai Y, Yoshida K, Tsukada K et al. Inapparent carcinoma of the gallbladder. An appraisal of a radical second operation after simple cholecystectomy. Ann Surg 1992; 215(4): 326-331.

47. Baxter I, Garden OJ. Surgical palliation of carcinoma of the gallbladder. Hepatogastroenterology 1999; 46(27): 1572-1577.

48. Todoroki T, Kawamoto T, Takahashi H et al. Treatment of gallbladder cancer by radical resection. Br J Surg 1999; 86(5): 622-627. 